\title{
Novel Necrotrophic Effectors from Stagonospora nodorum and Corresponding Host Sensitivities in Winter Wheat Germplasm in the Southeastern United States
}

\author{
A. D. Crook, T. L. Friesen, Z. H. Liu, P. S. Ojiambo, and C. Cowger
}

First and fourth authors: Department of Plant Pathology, North Carolina State University, Raleigh, NC 27695; second author: Northern Crop Science Laboratory, U.S. Department of Agriculture-Agricultural Research Service (USDA-ARS), Fargo, ND 58105; third author: Department of Plant Pathology, North Dakota State University, Fargo 58108; and fifth author: USDA-ARS, Department of Plant Pathology, North Carolina State University, Raleigh 27695.

Current address of A. D. Crook: Department of Genetics and Biochemistry, Clemson University, Clemson, SC 29634.

Accepted for publication 1 January 2012.

\begin{abstract}
Crook, A. D., Friesen, T. L., Liu, Z. H., Ojiambo, P. S., and Cowger, C. 2012. Novel necrotrophic effectors from Stagonospora nodorum and corresponding host genes in winter wheat germplasm in the southeastern United States. Phytopathology 102:498-505.

Stagonospora nodorum blotch (SNB), caused by the necrotrophic fungus Stagonospora nodorum (teleomorph: Phaeosphaeria nodorum), is among the most common diseases of winter wheat in the United States. New opportunities in resistance breeding have arisen from the recent discovery of several necrotrophic effectors (NEs, also known as hostselective toxins) produced by $S$. nodorum, along with their corresponding host sensitivity (Snn) genes. Thirty-nine isolates of $S$. nodorum collected from wheat debris or grain from seven states in the southeastern United States were used to investigate the production of NEs in the region. Twenty-nine cultivars with varying levels of resistance to SNB, representing 10 eastern-U.S. breeding programs, were infiltrated with culture filtrates from the $S$. nodorum isolates in a randomized complete block design. Three single-NE Pichia pastoris controls, two S. nodorum isolate controls, and six Snn-differential wheat controls were also used. Cultivarisolate interactions were visually evaluated for sensitivity at 7 days after infiltration. Production of NEs was detected in isolates originating in each

sampled state except Maryland. Of the 39 isolates, 17 produced NEs different from those previously characterized in the upper Great Plains region. These novel NEs likely correspond to unidentified Snn genes in Southeastern wheat cultivars, because NEs are thought to arise under selection pressure from genes for resistance to biotrophic pathogens of wheat cultivars that differ by geographic region. Only 3, 0 , and $23 \%$ of the 39 isolates produced SnToxA, SnTox1, and SnTox3, respectively, by the culture-filtrate test. A Southern dot-blot test showed that 15, 74, and $39 \%$ of the isolates carried the genes for those NEs, respectively; those percentages were lower than those found previously in larger international samples. Only two cultivars appeared to contain known Snn genes, although half of the cultivars displayed sensitivity to culture filtrates containing unknown NEs. Effector sensitivity was more frequent in SNB-susceptible cultivars than in moderately resistant (MR) cultivars $(P=0.008)$, although some susceptible cultivars did not exhibit sensitivity to NEs produced by isolates in this study and some MR cultivars were sensitive to NEs of multiple isolates. Our results suggest that NE sensitivities influence but may not be the only determinant of cultivar resistance to $S$. nodorum. Specific knowledge of NE and Snn gene frequencies in this region can be used by wheat breeding programs to improve SNB resistance.
\end{abstract}

Stagonospora nodorum blotch (SNB), caused by the necrotrophic fungal pathogen Stagonospora nodorum (Berk.) E. Castell. \& Germano (teleomorph: Phaeosphaeria nodorum (E. Müll.) Hedjar.), is a widely distributed disease of winter wheat (Triticum aestivum L.) in the United States and other wheatgrowing areas in the world. The disease is favored by warm temperatures and high humidity, and can increase rapidly in the southeastern United States during stem elongation, spike emergence, and early grain-fill. In addition to small to moderate yield losses, SNB can reduce grain quality and test weight $(2,25)$. SNB has become an increasingly important disease of wheat worldwide due to increased wheat production, the growing of SNB-susceptible cultivars, and changes in cultural practices, including the increased use of nitrogen fertilizers and the switch to reduced tillage or no-till cultivation (6).

Corresponding author: C. Cowger; E-mail address: Christina.Cowger@ars.usda.gov

http://dx.doi.org/10.1094/PHYTO-08-11-0238

This article is in the public domain and not copyrightable. It may be freely reprinted with customary crediting of the source. The American Phytopathological Society, 2012
A sustainable and cost-effective option to manage SNB is the use of resistant cultivars. Many commercial cultivars are susceptible, while some exhibit moderate or high levels of partial resistance (23). Since 2007, the latest advanced experimental lines from the eastern United States have been screened each year for resistance to SNB in the Eastern U.S. Septoria Nursery and the results posted at the web site of the Plant Science Research Unit of the United States Department of Agriculture-Agricultural Research Service (USDA-ARS) in Raleigh, NC. This screening has contributed to the development of germplasm with improved resistance to SNB as well as other traits (4).

Breeding for resistance to SNB is hampered by unreliable disease pressure and the complexity of the SNB-wheat pathosystem. Several field studies have shown that resistance to SNB is quantitatively inherited $(5,9,29)$. However, other recent studies have shown that an important component of SNB resistance operates in the framework of a qualitative "inverse gene-for-gene" interaction involving necrotrophic effectors (NEs), also known as host-selective toxins $(10,12,16,18,20,24)$. These discoveries have made the wheat-S. nodorum pathosystem an emerging model for understanding how NEs "hijack" host resistance pathways $(10,15$, $25,30)$. The hijacked genes, which are thought to be resistance $(R)$ genes that trigger programmed cell death $(8,13)$, may have been 
deliberately introgressed into the wheat germplasm for their ability to confer resistance to other biotrophic diseases or pests. NEs have been shown to be factors in susceptibility at boot stage as well as in seedlings (10).

Due to the availability of the genome sequence of $S$. nodorum, the SNB-wheat NE system offers insight into how effectorproducing necrotrophic fungi induce disease $(11,13)$. To date, five $S$. nodorum-derived proteinaceous NEs (SnToxA, SnTox1, SnTox2, SnTox3, and SnTox4) and corresponding host sensitivity loci (Tsn1, Snn1, Snn2, Snn3, and Snn4) have been named and characterized in the SNB-wheat system $(1,13-15,18,21)$. The discovery of $S$. nodorum NEs has the potential to provide useful new information for resistance breeding. For example, sensitivity genes in the host could be identified in order to facilitate their removal. However, the fungal isolates and wheat cultivars currently available for identifying named NEs and Snn genes originated in the hard spring wheat region of the north-central United States (12), and could be different from effectors produced by isolates from other regions. Our goal was to determine whether NEs are produced by $S$. nodorum isolates in the southeastern United States and whether sensitivity genes are present in wheat germplasm from the region. The term "sensitivity" will refer to host sensitivity to effectors per se, and the term "susceptibility" to overall host response to $S$. nodorum.

\section{MATERIALS AND METHODS}

Test cultivars. To determine whether sensitivity genes are present in southeastern U.S. wheat germplasm, a representative sample of cultivars was selected. Twenty-one red winter wheat lines from breeding programs in 10 southeastern U.S. states were chosen for the present study due to previously observed high levels of either resistance or susceptibility to SNB in the Eastern U.S. Septoria Nursery managed by the USDA-ARS (Table 1). Most of the entries were advanced experimental lines. Briefly, each cultivar had been planted in a randomized complete block design, with two replicate plots at each of three locations (Plains, GA; Kinston, NC; and Salisbury, NC), and each plot consisted of two adjacent $1.1-\mathrm{m}$ rows. Epidemics were caused by naturally occurring $S$. nodorum populations. The cultivars were rated on a whole-canopy basis at late-milk to early-dough stage, using a visual scale of 1 to 9 , with 1 being the most susceptible and 9 being the most resistant (the highest level of partial resistance). Three commercial soft red winter wheat cultivars that served as controls in the Septoria Nursery were also included in this study: 'NC-Neuse' (moderately resistant [MR]), 'USG3209' (moderately susceptible [MS]), and 'AGS2000' (susceptible [S]).

To prevent seedborne infection and increase germination efficiency, seed of all lines was surface-sterilized with $95 \%$ ethanol for $20 \mathrm{~s}$ and then $10 \%$ sodium hypochlorite for $1 \mathrm{~min}$, and was then rinsed with distilled water for $20 \mathrm{~s}$ before planting. Wheat cultivars were grown in low-density cone-tainers potted with $2 \mathrm{M}$ lightweight mix (Conrad Fafard, Inc., Agawam, MA) in a greenhouse with an average temperature of $22^{\circ} \mathrm{C}$.

Six wheat lines or cultivars ('BR34', 'M-6', 'BG223', 'BG220', 'BG261', and 'Grandin') were used as differentials for effector sensitivity (Table 2). BR34 is a Brazilian hard red spring wheat (HRSW) that is highly resistant to most North American $S$. nodorum isolates (10). The HRSW Grandin is susceptible to most North American $S$. nodorum isolates tested and is known to contain Tsn1, Snn2, and Snn3 (10). BG261, BG223, and BG220 are recombinant inbred lines (RILs), resulting from a cross between BR34 and Grandin, that display differential sensitivity to SnToxA (14), SnTox2 (13), and SnTox3 (15), respectively.

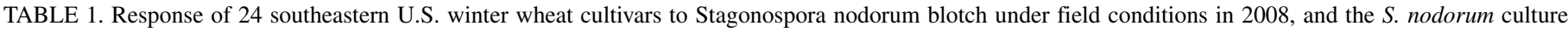
filtrates to which they exhibited a sensitive reaction

\begin{tabular}{|c|c|c|c|c|c|c|}
\hline Cultivar, line ${ }^{a}$ & Breeding program & State $^{b}$ & $\begin{array}{l}\text { Disease } \\
\text { rating }^{c}\end{array}$ & $\begin{array}{c}\text { Resistance } \\
\text { designation }^{\mathrm{d}}\end{array}$ & $\begin{array}{l}\text { Number of } \\
\text { toxic isolates } \\
(\text { out of } 39)^{\mathrm{e}}\end{array}$ & $\begin{array}{l}\text { Sensitive to control } \\
\text { culture filtrate }\end{array}$ \\
\hline NC-Neuse & North Carolina State University & $\mathrm{NC}$ & 1.8 & MR-CHK & 5 & None \\
\hline LA $01 * 425$ & Westbred LLC & IN & 1.0 & MR & 9 & None \\
\hline B030543 & Syngenta Seeds & AR & 1.2 & MR & 0 & None \\
\hline MD00W389-07-2 & University of Maryland & MD & 1.3 & MR & 0 & None \\
\hline NC05-22804 & North Carolina State University & $\mathrm{NC}$ & 1.3 & MR & 1 & None \\
\hline TN801 & University of Tennessee & $\mathrm{TN}$ & 1.3 & MR & 0 & None \\
\hline VA05W-376 & Virginia Polytechnic Institute and State University & VA & 1.3 & MR & 0 & None \\
\hline KY97C-0508-01-01A-1 & University of Kentucky & KY & 1.5 & MR & 0 & None \\
\hline NC-Yadkin & North Carolina State University & $\mathrm{NC}$ & 1.5 & MR & 8 & None \\
\hline AR99095-18-1 & University of Arkansas & AR & 1.8 & MR & 0 & None \\
\hline GA00190-7A14 & University of Georgia & GA & 1.8 & MR & 0 & None \\
\hline USG3209 & Uni-South Genetics & VA & 3.0 & MS-CHK & 0 & None \\
\hline AR99136-13-2 & University of Arkansas & AR & 3.2 & MS & 1 & None \\
\hline Pembroke & University of Kentucky & KY & 3.3 & MS & 2 & Sn4, Sn6 \\
\hline VA05W-168 & Virginia Polytechnic Institute and State University & VA & 3.7 & MS & 7 & None \\
\hline AGS2000 & University of Georgia & GA & 5.7 & $\mathrm{~S}-\mathrm{CHK}$ & 5 & Sn6 \\
\hline VA05W-125 & Virginia Polytechnic Institute and State University & VA & 4.3 & S & 0 & None \\
\hline NC05-24112 & North Carolina State University & $\mathrm{NC}$ & 4.5 & $\mathrm{~S}$ & 11 & None \\
\hline ARS05-0242 & USDA-ARS, Raleigh & $\mathrm{NC}$ & 4.7 & $\mathrm{~S}$ & 16 & P.p.-SnTox3, Sn4, Sn6 \\
\hline LA01110D-251 & Louisiana State University & LA & 4.8 & $\mathrm{~S}$ & 0 & None \\
\hline GA001271-10-3-5 & University of Georgia & GA & 5.2 & $\mathrm{~S}$ & 1 & Sn6 \\
\hline SCW98008PI & Clemson University & $\mathrm{SC}$ & 6.0 & $\mathrm{~S}$ & 0 & None \\
\hline MD00-W16-07-3 & University of Maryland & MD & 6.2 & $\mathrm{~S}$ & 8 & Sn4, Sn6 \\
\hline KY01C-1177-06 & University of Kentucky & KY & $\ldots$ & $\mathrm{S}$ & 0 & None \\
\hline
\end{tabular}

a All cultivars are soft wheats except ARS05-0242, a hard wheat.

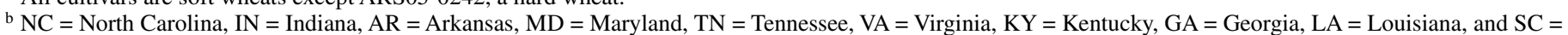
South Carolina.

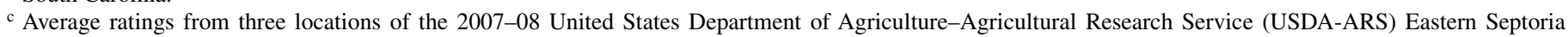

Nursery (Plains, GA; Kinston, NC; and Salisbury, NC) using a visual scale of 1 (highest level of partial resistance) to 9 (susceptible).

${ }^{\mathrm{d}}$ Resistance designation based on field ratings: $\mathrm{S}=$ susceptible, $\mathrm{MS}=$ moderately susceptible, $\mathrm{MR}=$ moderately resistant, and CHK $=$ check.

e $S$. nodorum isolates from Arkansas, Georgia, Maryland, North Carolina, South Carolina, Tennessee, and Virginia.

f S. nodorum isolates Sn4 and Sn6 produced SnTox2 and SnTox3; P.p.-SnTox3 = Pichia pastoris strain engineered to produce SnTox3.

g Cultivar was not in the 2007-08 Eastern Septoria Nursery; resistance level based on 2008-09 resistance screening in the Eastern Septoria Nursery. 
W7984 (M6) is a synthetic wheat line that exhibits sensitivity to SnTox1 (17).

$S$. nodorum isolates. To determine if NEs are produced by $S$. nodorum isolates in the southeastern United States, a representative sample of isolates was gathered. Fungal isolates were derived from wheat stubble collected from one location each in Georgia (Griffin), Maryland (Quantico), South Carolina (Clemson), Tennessee (Knoxville), and Virginia (Blacksburg), and two locations in North Carolina (Salisbury and Kinston). The stubble was transported by mail or courier to the USDA-ARS lab at North Carolina State University. Leaf samples that had visible lesions with pycnidia were chosen from the stubble, surface sterilized using ethanol and $10 \%$ sodium hypochlorite as described above, and placed in moist chambers for $24 \mathrm{~h}$ to promote sporulation of $S$. nodorum. Moist chambers consisted of 9-cm-diameter glass petri dishes containing 9-cm-diameter filter papers moistened with sterile distilled water. After $24 \mathrm{~h}$, leaf sections were examined using a stereomicroscope under a laminar air-flow hood for the presence of pycnidia with oozing cirrhi. The spore masses were removed using a sterilized inoculation needle and plated on potato dextrose agar (PDA). No isolates could be obtained from Arkansas wheat debris; therefore, a set of $S$. nodorum cultures was kindly provided by Dr. Gene Milus, University of Arkansas. These cultures had been isolated in Arkansas from infected wheat seed in 1995 and preserved on silica gel at $-80^{\circ} \mathrm{C}$.

In total, 39 isolates with unknown NE production were derived from the six states (Table 3 ) for use in this study. Two additional fungal isolates were used as controls because they produce known NEs: Sn4 produces SnToxA, SnTox1, SnTox2, and SnTox3 (19) (T. L. Friesen and Z. H. Liu, unpublished); and Sn6 possesses the SnToxA, SnTox1, SnTox2 (13), and SnTox3 genes and produces SnTox2 and SnTox3 in culture (Table 2) (19).

Preparation of culture filtrates. Fungal isolates, including controls, were grown on PDA for 7 days. For each isolate, mycelial plugs were transferred to an Erlenmeyer flask containing $50 \mathrm{ml}$ of Fries medium (18), enclosed in aluminum foil to maintain darkness, and placed on an orbital shaker at $80 \mathrm{rpm}$ for $48 \mathrm{~h}$, followed by 3 weeks of stationary growth. Culture filtrates (CFs) were collected using vacuum filtration through a Whatman number 1 filter, followed by filtration through 0.80 - and $0.45-\mu \mathrm{m}$ membrane syringe filters.

Three cultures of the yeast Pichia pastoris that had been engineered to express SnToxA (14), SnTox1 (21), or SnTox3 (19) were used as positive controls (Table 2). They will be referred to here as P.p.-SnToxA, P.p.-SnTox1, and P.p.-SnTox3, respectively. $P$. pastoris cultures were grown and maintained on yeast peptone dextrose (YPD) (1\% yeast extract, $2 \%$ peptone, and 2\% dextrose). Yeast cultures were prepared by culturing a single colony of each of the engineered P. pastoris yeast strains in $1 \mathrm{ml}$ of YPD for $48 \mathrm{~h}$ at $30^{\circ} \mathrm{C}$ on an orbital shaker at $220 \mathrm{rpm}$. The resulting yeast culture $(200 \mu \mathrm{l})$ was placed in a fresh tube containing $10 \mathrm{ml}$ of YPD and allowed to propagate at $30^{\circ} \mathrm{C}$ for $48 \mathrm{~h}$ on an orbital shaker at $220 \mathrm{rpm}$. The sample was then centrifuged at $13,000 \times \mathrm{g}$ for $5 \mathrm{~min}$ and the resultant supernatant was passed through a $0.45-\mu \mathrm{m}$ filter for sterilization and used for inoculation.

CF analysis of test lines. To characterize the interactions between the 24 test lines and the 39 S. nodorum isolates, at the two- to three-leaf stage, the second leaves of three replicate plants of each test cultivar were infiltrated with $\approx 50 \mu \mathrm{l}$ of CFs of fungal isolates, or with a yeast control culture, using a 3-ml syringe with the needle removed. The margins of the water-soaked area were immediately marked using a nontoxic felt marker. After infiltration, all plants were moved to a growth chamber at $21^{\circ} \mathrm{C}$ and with a 12-h photoperiod. The infiltrated leaves were scored as either sensitive, chlorotic, or insensitive 7 days after infiltration (Fig. 1). Leaves with heavy necrosis and deformation of the leaf tissue were characterized as sensitive. Intermediate, chlorotic interactions may reflect different levels of affinity for host recep-

TABLE 3. Stagonospora nodorum isolates from the southeastern United States, and percentage of moderately resistant (MR) versus moderately susceptible and susceptible (MS/S) southeastern wheat cultivars sensitive to necrotrophic effectors (NEs) in culture filtrates (CFs) of those isolates

\begin{tabular}{lcccc}
\hline & & \multicolumn{2}{c}{ Number of effector-sensitive cultivars ${ }^{\mathrm{a}}$} \\
\cline { 3 - 5 } Isolate, effector & $\begin{array}{c}\text { Number of } \\
\text { isolates }\end{array}$ & $\begin{array}{c}\text { MR } \\
(\mathrm{n}=11)\end{array}$ & $\begin{array}{c}\text { MS/S } \\
(n=13)\end{array}$ & $\begin{array}{c}\text { Total } \\
(n=24)\end{array}$ \\
\hline State & & & & \\
Arkansas & 6 & 1 & 4 & 5 \\
Georgia & 5 & 2 & 5 & 7 \\
Maryland & 3 & 0 & 0 & 0 \\
North Carolina & 11 & 3 & 7 & 10 \\
South Carolina & 4 & 0 & 1 & 1 \\
Tennessee & 5 & 2 & 2 & 4 \\
Virginia & 5 & 3 & 4 & 7 \\
Total & 39 & 4 & 8 & 0 \\
Effector & & & & 0 \\
SnToxA & $\ldots$ & 0 & 0 & 1 \\
SnTox1 & $\ldots$ & 0 & 0 & 12 \\
SnTox3 & $\ldots$ & 0 & 1 & 12 \\
Uncharacterized $^{\mathrm{d}}$ & $\ldots$ & 4 & 8 & 0 \\
No sensitivity $^{\mathrm{e}}$ & $\ldots$ & 7 & 5 & 0
\end{tabular}

a Number of cultivars sensitive to NEs in CFs from any isolates from the state, or to specific NEs, where MR and MS/S are based on field evaluations in the Eastern U.S. Septoria Nursery (2007-08).

b State of origin of isolate.

c NEs in CFs of Pichia pastoris strains engineered to express SnToxA, SnTox 1, or SnTox3.

${ }^{\mathrm{d}}$ Uncharacterized effectors. Sensitivity to CFs of 1 or more of the 39 southeastern isolates in a line insensitive to all P. pastoris and S. nodorum controls.

e Exhibited no detectable sensitivity to CFs used in this study.

TABLE 2. Effector-producing Pichia pastoris cultures, Stagonospora nodorum isolates, and differential wheat lines used as controls in study of necrotrophic effector sensitivity in southeastern U.S. wheat

\begin{tabular}{|c|c|c|c|c|c|c|}
\hline \multirow[b]{3}{*}{ Cultivar $^{\mathrm{a}}$} & \multirow[b]{3}{*}{ Sensitivity gene } & \multicolumn{5}{|c|}{ Observed interaction $^{\mathrm{b}}$} \\
\hline & & \multicolumn{3}{|c|}{ Effector-expressing Pichia cultures ${ }^{c}$} & \multicolumn{2}{|c|}{ S. nodorum control isolates ${ }^{\mathrm{d}}$} \\
\hline & & SnToxA & SnTox1 & SnTox3 & Sn4 & Sn6 \\
\hline BG261 & $T s n 1$ & S & I & I & I & I \\
\hline M-6 & Snn1 & I & $\mathrm{S}$ & I & I & $\ldots$ \\
\hline BG223 & Snn2 & I & I & I & $\mathrm{S}$ & $\mathrm{S}$ \\
\hline BG220 & Snn3 & I & I & $\mathrm{S}$ & $\mathrm{S}$ & $S$ \\
\hline
\end{tabular}


tors by $S$. nodorum effectors (1), or low concentrations of the effector in the infiltrated solution. In the present study, only fully sensitive ratings at 7 days after inoculation were subjected to analysis, in order to focus on major interactions. There were three replicates of each cultivar-isolate combination.

CF analysis of commercial cultivars. To explore whether NE sensitivity might play a role in SNB susceptibility observed in commercially grown varieties, five soft red winter wheat cultivars (Table 4) were chosen based on their SNB susceptibility (3). These cultivars are each grown commercially on substantial wheat area in the southeastern United States, although there is no official system for determining wheat variety hectareages. At the two- to three-leaf stage, the second leaf of each cultivar was infiltrated with filtrate from each of 23 isolates ( 9 isolates from North Carolina, 4 from South Carolina, and 5 each from Georgia and Tennessee) chosen as a sample of the 39 previously described

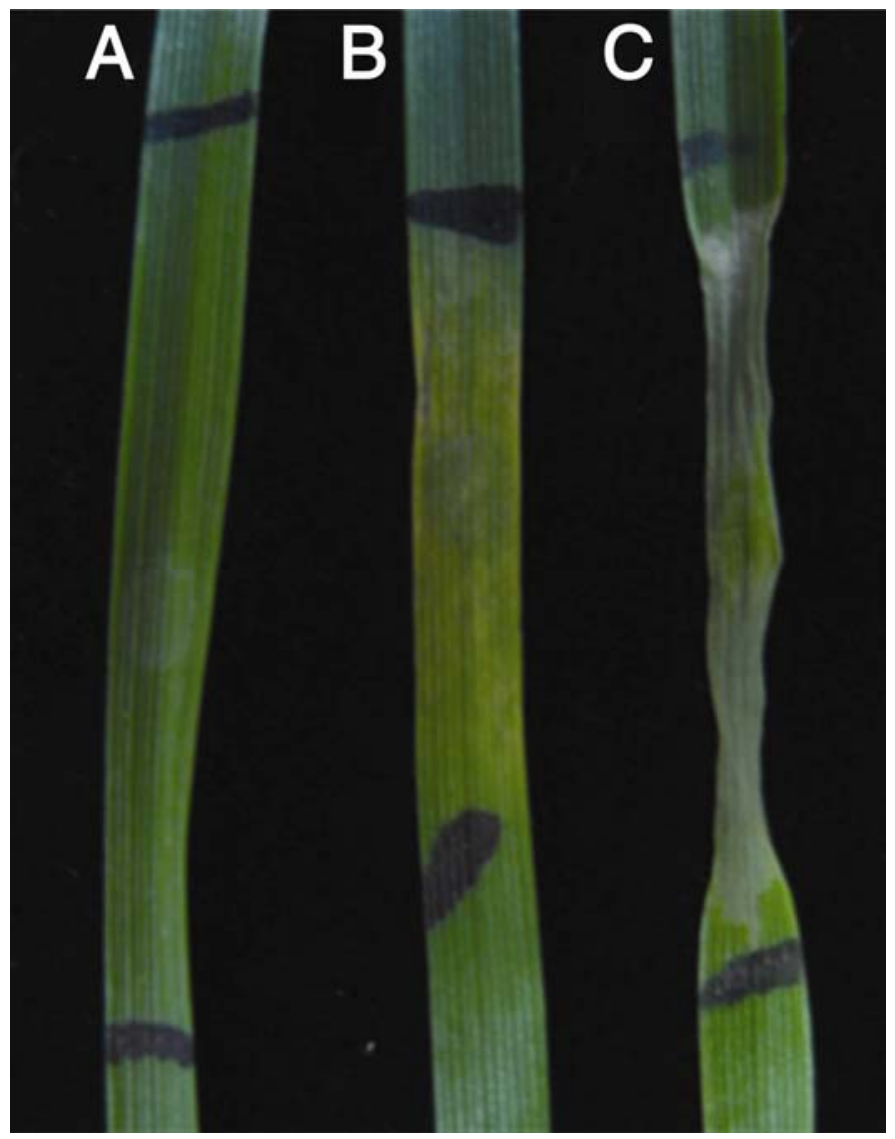

Fig. 1. Visual scale used to rate the reaction of wheat cultivars to necrotrophic effectors produced by 39 Stagonospora nodorum isolates from the southeastern United States: A, insensitive; $\mathbf{B}$, chlorotic; or $\mathbf{C}$, sensitive reaction. isolates. The P.p.-SnToxA, P.p.-SnTox1, and P.p.-SnTox3 controls described above were also used in this experiment. Three replicates were used for each cultivar-isolate combination.

Genetic analysis of $\boldsymbol{S}$. nodorum isolates. Dot blot analysis was used to investigate the presence or absence of the three effector genes SnToxA, SnToxl, and SnTox3 in the 39 S. nodorum isolates (no probe was available for $S n T o x 2$, because this gene had not yet been cloned.) DNA was extracted from each isolate using the Qiagen DNeasy Plant kit (Qiagen, Valencia, CA) or a cetyltrimethylammonium bromide extraction protocol (22). The DNA samples were prepared and blotted onto a nylon membrane using a Bio-Dot microfiltration apparatus (Bio-Rad) following the manufacturer's instructions. The entire coding regions of SnToxA, SnToxl, and SnTox3 were polymerase chain reaction amplified from the genomic DNA of S. nodorum isolate SN15 (19) and used as probe in Southern blot analysis for each effector gene. Probes preparation, DNA hybridization, membrane washing, and image acquisition followed the protocol described by Faris et al. (7).

Statistical analysis. The PROC FREQ procedure in SAS (version 9.1.3; SAS Institute, Cary, NC) was used to perform Pearson's $\chi^{2}$ test to determine whether effector sensitivity was associated with level of cultivar resistance. The same procedure was used to evaluate whether there was evidence of adaptation by isolates from a given state to cultivars bred in that state.

The genotype-environment interaction (GGE) biplot analysis was conducted using the GGE biplot software program (31) to visualize the clustering of isolates by effector-production profile and of cultivars by effector-sensitivity profile. A biplot is a scatter plot for graphic display of a matrix approximating a two-way table, using the first two principal components, PC1 and PC2. The analysis was performed for the results of the $\mathrm{CF}$ experiment, not with the data from the dot-blot test. Cultivars that were not sensitive to filtrates in this study, and one cultivar that was sensitive to filtrate of only one isolate, were depicted by the software at the origin of the horizontal and vertical lines in the biplot, and were omitted in the final presentation of the results. Similarly, $S$. nodorum isolates that produced no NEs to which cultivars used in this study were sensitive appeared at the origin of the horizontal and vertical lines, and were omitted in the presentation of the results.

\section{RESULTS}

NE production. At least one $S$. nodorum isolate from each state except Maryland showed some production of NEs in culture (Table 5). One-third (13 of 39) of the isolates did not produce NEs to which any of the 24 cultivars were sensitive (Table 5).

SnToxA was produced in CF of only one isolate, GA 9-3, which originated in Georgia (Table 5); the corresponding wheat Tsn1 differential (BG261) responded sensitively, as expected, to P.p.-SnToxA (Table 2) and to isolate GA 9-3. The Snn1 wheat differential line M6 was sensitive to CF from the P.p.-SnTox1

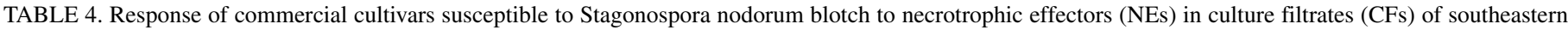
U.S. Stagonospora nodorum isolates

\begin{tabular}{|c|c|c|c|c|c|c|c|c|}
\hline \multirow[b]{2}{*}{ Cultivar $^{\mathrm{a}}$} & \multirow[b]{2}{*}{ PI/PVP number } & \multicolumn{3}{|c|}{ NE sensitivity ${ }^{b}$} & \multicolumn{4}{|c|}{ Number of isolates toxic ${ }^{c}$} \\
\hline & & SnToxA & SnTox 1 & SnTox 3 & $\mathrm{GA}(n=5)$ & $\mathrm{NC}(n=9)$ & $\mathrm{SC}(n=4)$ & $\mathrm{TN}(n=5)$ \\
\hline Jamestown & PI 653731 & I & I & I & 0 & 0 & 0 & 0 \\
\hline Magnolia & PVP 200700248 & I & $\mathrm{S}$ & I & 1 & 1 & 3 & 1 \\
\hline Panola & PVP 200500196 & I & I & I & 0 & 0 & 0 & 0 \\
\hline SS520 & PI 619052 & I & I & I & 0 & 0 & 0 & 0 \\
\hline SSMPV57 & PI 639506 & I & I & I & 0 & 0 & 0 & 0 \\
\hline
\end{tabular}

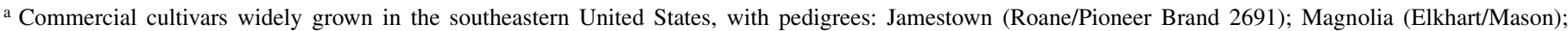

Panola (E87-6646/Pio2580); SS520 (FFR555W/GA Gore); and SSMPV 57 (FFR555W/VA89-22-52).

b Sensitive (S) or insensitive (I) reaction to CFs from Pichia pastoris strains engineered to express the NEs.

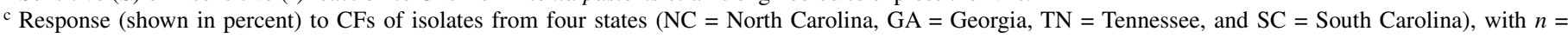
number of isolates tested per state. 
strain, as expected, and insensitive to CF from all 39 experimental $S$. nodorum isolates. The Snn2 wheat differential line, BG223, was insensitive to $\mathrm{CF}$ from all $39 \mathrm{~S}$. nodorum isolates but sensitive to CF from the two SnTox2-producing control isolates, $\mathrm{Sn} 4$ and Sn6. Taken together, these data indicate that the isolates in this collection did not produce SnTox 1 or SnTox 2 in culture, or they produced forms of the effectors to which the Snnl and Snn2 differentials were not sensitive.

As for SnTox3, the Snn 3 controls BG220 and Grandin were sensitive to CFs from the appropriate controls and 9 and 8 of the 39 isolates, respectively. Thus, $23 \%$ of the 39 S. nodorum isolates in this study produced this NE either alone or in combination with other effectors, making SnTox3 the most prevalent of the characterized NEs produced by the Southeastern isolates as detected in the CF test (Table 5). The region was broadly represented in the production of SnTox3, because these nine isolates had origins in six of the seven states sampled.

Results of the dot-blot analysis of the $39 \mathrm{~S}$. nodorum isolates are shown in Table 5. SnToxA was found to be present in $15 \%$ of the isolates, SnToxl in 74\%, and SnTox3 in 39\%. There were no cases where an isolate was positive on a given control in the $\mathrm{CF}$ analysis and negative for the corresponding NE gene in the dotblot analysis.

NE sensitivity. Sensitivity to effectors produced by $S$. nodorum isolates in this study was present in both MR and moderately MS or S cultivars (Tables 1 and 3). The percentage of isolates that produced CFs toxic to a particular cultivar was 0 to $41 \%$ (Table 1). Half of the cultivars had sensitivities to uncharacterized NEs, with eight of such cultivars having an SNB-susceptible phenotype (Table 3). The targets for these effectors are presumably unidentified sensitivity genes in the host.

Based on response to P.p.-SnTox1 CFs, the host sensitivity gene Snnl was not detected in any of the 24 cultivars discussed in Tables 1 and 3. As for Snn2, there was no P. pastoris control but CFs from Sn6 induced sensitive reactions in five cultivars, three of which were also sensitive to CFs from Sn4 (Table 1). Only one of the five cultivars was shown by response to P.p.-SnTox3 to possess Snn3; therefore, it is possible that Snn2 was present in this group. The cultivar bearing Snn3, 'ARS05-0242', was the only hard red winter wheat used in this study. This SNB-susceptible cultivar with pedigree Coker9835/RL6042//TX99D4657 was bred in North Carolina using a hard wheat from Texas as one of the parents. ARS05-0242 possesses the leaf rust (caused by Puccinia triticina) $R$ gene $L r 3 b g$ and the stem rust (caused by $P$. graminis f. sp. tritici) $R$ genes $\operatorname{Sr} 36$ and $\operatorname{SrlA} .1 R$ (D. Marshall, personal communication).

Only one of the five SNB-susceptible commercial cultivars challenged with filtrates from the 23-isolate subset exhibited sensitivity to CFs; namely, to SnTox1 (Table 4). 'Magnolia' had sensitive reactions to P.p.-SnTox1, indicating that Magnolia possesses Snn1, and to at least one isolate from each state. Two of the six isolates to which Magnolia was sensitive did not carry SnToxl according to the dot-blot test; therefore, Magnolia possesses another Snn gene (which is not Tsn1 or Snn3) in addition to Snn1. The parentage of Magnolia, which includes soft red wheat cultivars 'Elkhart', 'Mason', and 'Cardinal', traces to the U.S. states of Indiana and Ohio. Few North American wheat lines have been shown to possess Snnl (T. Friesen, personal observation).

State-level adaptation and relationship of sensitivity to susceptibility. There was no significant $(P>0.05)$ trend for $S$. nodorum isolates from a given state to be toxic to cultivars bred in that state more often than to cultivars from other states, except in the case of North Carolina, where a significant association $\left(\chi^{2}=\right.$ $6.70, P=0.01)$ was observed.

If $\mathrm{NE}$ interactions play a significant role in pathogenesis and disease development, one would expect to find a greater degree of NE sensitivity among lines that are susceptible in the field than among those that are resistant. The $\chi^{2}$ analysis of association between level of cultivar resistance to SNB and frequency of sensitivity was significant $\left(\chi^{2}=7.04, P=0.008\right)$, indicating that susceptible cultivars had a higher frequency of sensitivity than did resistant cultivars. However, five MR cultivars (NC-Neuse, 'NCYadkin', 'NC05-22804', and 'LA01*425') were each sensitive to NEs from multiple $S$. nodorum isolates. Conversely, four susceptible cultivars were not sensitive to any of the NEs produced by isolates in this study.

NE production or sensitivity clusters. Cultivars and isolates were grouped by GGE biplot based on patterns of effector sensitivity and production detected in the CF test (Fig. 2). Five distinct clusters, most including both susceptible and MR cultivars, were identified by this analysis and are shown in boxes. Cultivars clustered based on the isolates that produced effectors to which they were sensitive and are positioned in the diagram based on the number of such isolates. For example, cluster 1 cultivars were usually sensitive to the same isolates, even though they differed strongly in susceptibility to SNB. Cluster 2 contains the MR NCYadkin and the susceptible 'VA05W-168', which are grouped because they had similar responses of sensitivity or insensitivity to most isolates. The six cultivars in clusters 1,2 , and 5 , which are displayed toward the right on the PC1 axis, were all sensitive to the highest proportions of isolates in our study. Both cultivars in cluster 4 were insensitive to SnTox 3 but sensitive to other effectors produced by numerous SnTox3-producing isolates.

Two distinct clusters of $S$. nodorum isolates were also identified in this study (Fig. 2). Cluster A consisted mainly of $S$. nodorum isolates from North Carolina and Georgia, which produced the highest frequency of sensitive reactions in the CF assay, while cluster B consisted of $S$. nodorum isolates that were shown to produce SnTox3.

TABLE 5. Characterized and uncharacterized necrotrophic effectors (NEs) produced by Stagonospora nodorum isolates sampled from southeastern U.S. states

\begin{tabular}{|c|c|c|c|c|c|c|c|c|}
\hline \multirow[b]{2}{*}{ NEs } & \multicolumn{8}{|c|}{ Number of $S$. nodorum isolates ${ }^{\mathrm{a}}$} \\
\hline & $\begin{array}{c}\text { Arkansas } \\
(n=6)\end{array}$ & $\begin{array}{c}\text { Georgia } \\
(n=5)\end{array}$ & $\begin{array}{c}\text { Maryland } \\
(n=3)\end{array}$ & $\begin{array}{l}\text { North Carolina } \\
\quad(n=11)\end{array}$ & $\begin{array}{l}\text { South Carolina } \\
\qquad(n=4)\end{array}$ & $\begin{array}{c}\text { Tennessee } \\
\quad(n=5)\end{array}$ & $\begin{array}{l}\text { Virginia } \\
(n=5)\end{array}$ & $\begin{array}{c}\text { Total } \\
(n=39)\end{array}$ \\
\hline \multicolumn{9}{|l|}{ Characterized } \\
\hline SnTox 1 & $0[4]$ & $0[5]$ & $0[3]$ & $0[7]$ & $0[3]$ & $0[5]$ & $0[2]$ & 0 [29] \\
\hline SnTox 3 & $1[3]$ & $1[3]$ & $0[0]$ & $2[2]$ & $2[3]$ & $1[2]$ & $2[2]$ & $9[15]$ \\
\hline Uncharacterized $^{\mathrm{b}}$ & 2 & 5 & 0 & 6 & 0 & 1 & 3 & 17 \\
\hline
\end{tabular}

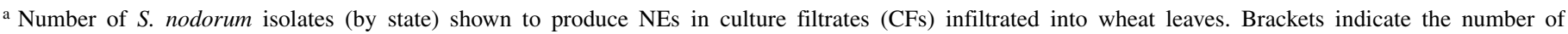

$S$. nodorum isolates found by Southern dot-blot analysis to carry the respective NE genes.

${ }^{\mathrm{b}}$ Wheat cultivars insensitive to all Pichia pastoris and S. nodorum controls were sensitive to CFs from these isolates.

c No NEs produced in culture to which any cultivars were sensitive.

d No toxic CFs or positive dot-blot results. 


\section{DISCUSSION}

This study was conducted to explore the diversity and importance of NE production by S. nodorum in the southeastern United States and generate information on the type and number of sensitivity genes present in elite germplasm in regional breeding programs. To our knowledge, this is the first effort to translate new findings on NEs in the $S$. nodorum-wheat model system into information useful to small-grain breeding programs in the southeastern United States.

Two-thirds of our isolate collection, including isolates from across the southeastern United States, produced NEs with corresponding sensitivities in the lines we tested, and most of these NEs had not been previously characterized. Through genetic analysis, we found that 15,74 , and $39 \%$ of our isolates carried SnToxA, SnTox1, or SnTox3, respectively. The relative frequencies of the three genes are consistent with results from studies of global populations, where SnToxA, SnToxl, and SnTox3 have been found in 24,85 , and $61 \%$ of $\approx 800$ isolates $(14,19,21)$. However, frequencies of all three characterized effector genes appear to be lower in the southeastern United States than in the global sample. It is possible that SnToxA, SnToxl, and SnTox3 would be detected more frequently in a larger sample of southeastern U.S. isolates. However, it seems equally likely that selection is the explanation for the lower frequencies. The biotic and abiotic stresses on wheat vary among regions and, therefore, wheat germplasm from one region possesses types and frequencies of disease $R$ genes that differ from those in germplasm from another region. Those genes are hypothesized to pleiotropically confer effector sensitivity. Therefore, it is plausible that $S$. nodorum isolates from the southeastern United States would produce a different suite of NEs corresponding to the sensitivity genes in Southeastern wheat germplasm, rather than to the genes common in another region.

The differences between our findings from the $\mathrm{CF}$ and genetic analyses, which were particularly pronounced in the case of SnTox1, may be attributable to gene expression and functionality. This set of S. nodorum isolates may contain the functional SnToxl effector gene but fail to produce the effector in artificial medium, which is commonly observed (T. Friesen, personal observation). Additionally, the NE may be produced in culture but not at a high enough concentration to cause a visible reaction or, alternatively, the protein may be produced but be unstable. Another possibility is that the isolates used in our study may have one or more different haplotypes of the SnToxl gene. In this scenario, different alleles would be present at the SnToxl and Snnl loci that do not interact strongly with the P.p.-SnTox1 and M6 controls.

Overall, susceptible cultivars exhibited a greater frequency of sensitivity than did resistant cultivars, indicating that NE-Snn interactions play a significant role in SNB resistance in the southeastern United States. However, previously characterized NEs and Snn genes do not appear to be important in the Southeast, on the basis of the present cultivar and isolate samples. We were able to identify three characterized sensitivity genes (Tsn1, Snn1, and Snn3) when they were present. However, no SnToxA sensitivity was found in any of the cultivars used in this study, and Snnl and Snn3 were putatively detected in just one cultivar each, both with significant portions of their pedigrees from outside the region. It is possible that a few of the 24 cultivars carry Snn2, given their sensitive response to control isolates $\mathrm{Sn} 4$ or $\mathrm{Sn} 6$, but we were unable to confirm this with the available controls and assays.

A large proportion of the sensitive interactions in this study were attributable to uncharacterized NEs and unknown sensitivity genes in the host. It is not surprising that a large number of novel interactions were found in a model host-pathogen system where the total number of characterized interactions far exceeds that of any other NE-driven pathosystem (11). We identified $S$. nodorum isolates in which NEs can be characterized and the corresponding targets in the host can be mapped. Knowledge of these sensitivity gene loci in the host could allow breeders to utilize markerassisted selection to "breed out" sensitivity genes if it can be determined that the resistance conferred to another pest or pathogen was not locally necessary or was redundant with resistance conferred by other genes. Of course, it would be desirable to know if an Snn gene is conferring resistance to a specific disease or pest and, if so, to which one. For our sample of 24 wheat cultivars, we examined available data from the USDA-ARS on molecular markers for resistance to pests such as Hessian fly and diseases such as stem and leaf rust. However, we were unable to identify particular postulated $R$ genes that would explain patterns of NE sensitivity found in the present study.

North Carolina was the only state whose isolates and cultivars gave evidence of local adaptation of NEs to wheat germplasm. Such adaptation may not have been detectable for other states due to breeding programs utilizing germplasm from out of state, or due to insufficient sample sizes (the North Carolina isolate sample was larger). The identification of the known effector sensitivity gene Snn3 in an elite line provides breeders with a potential opportunity to make improvements in resistance to SNB through marker-assisted selection against that gene.

Of the 39 isolates used in this study, only 1 produced SnToxA, which is consistent with the lack of the Tsn1 allele in any of the elite lines or commercial cultivars tested in this study. One of the best-characterized proteinaceous toxins, ToxA, was discovered in the tan spot fungus Pyrenophora tritici-repentis (28), and the gene is thought to have been laterally transferred from $S$. nodorum (SnToxA) to P. tritici-repentis (PtrToxA) some time before 1941 (14). Subsequent analysis of the $S$. nodorum population and the

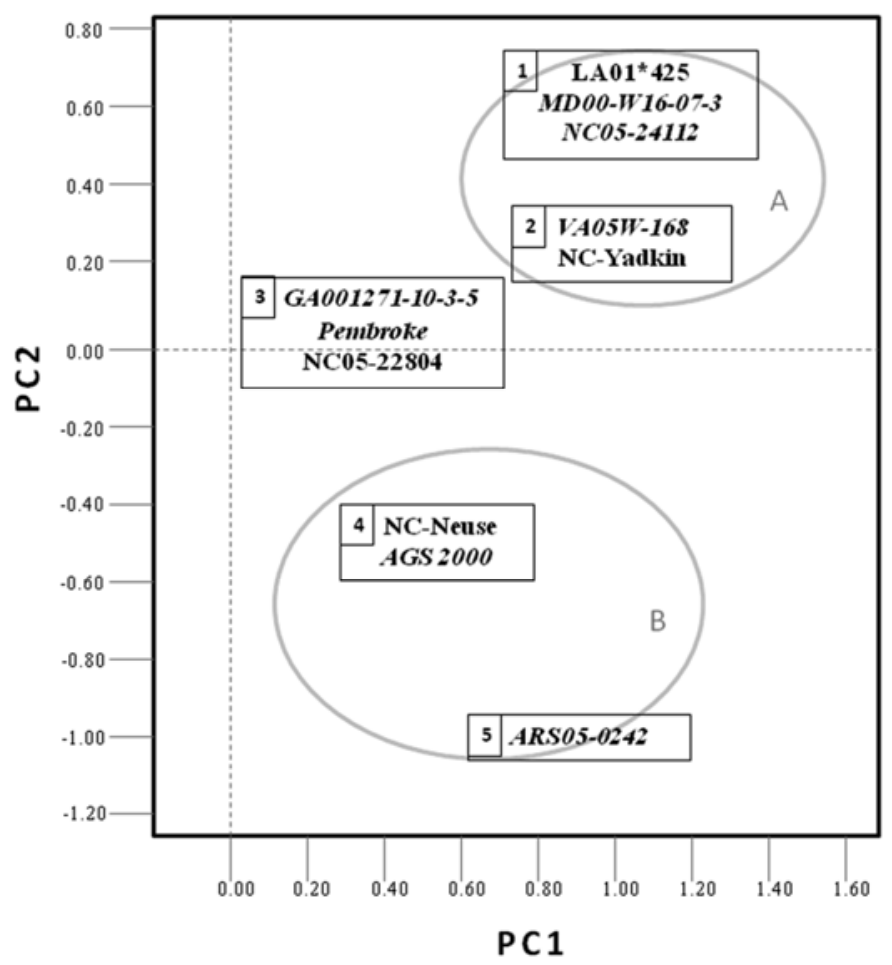

Fig. 2. Cluster analysis of interaction of southeastern U.S. wheat cultivars (squares) and necrotrophic effectors (NEs) produced by southeastern U.S. Stagonospora nodorum isolates (ovals), adapted from output of genotypeenvironment interaction (GGE) biplot analysis. Susceptible cultivars are italicized; moderately resistant cultivars are not. Cultivars clustered based on which and how many isolates produced culture filtrates toxic to them. Isolates clustered according to both geographical origin and NE production: Group A includes isolates mainly from North Carolina and Georgia, while Group B includes isolates capable of SnTox3 production. Not all isolates and cultivars are shown due to space limitations. $\mathrm{PC}=$ principal component. See text for details. 
production of SnToxA in eight major regions of the world showed a broad range of deletion frequencies at the SnToxA locus (26). Deletion frequencies ranged from 0\% (Australia) to 98\% (China), with several regions in the 50\% range, including Central America, Central Asia, the Middle East, and South Africa. High deletion frequencies are hypothesized to correspond to a fitness cost to the pathogen for carrying SnToxA in the absence of the Tsn1 allele and, thus, could be driven by local selection pressures (27). North American isolates exhibited a deletion frequency of $75 \%$ (26), not very different from the $85 \%$ found in the present study.

The frequency of sensitivity in cultivars with a susceptible SNB phenotype was found to be higher than cultivars with resistant SNB phenotypes, which supports previous findings (11) that NESnn interactions are prominent in pathogenesis and disease resistance. We did find instances in which susceptible cultivars were not sensitive to any NEs in CFs in the present study. However, these cultivars may be sensitive to NEs that are produced by some of the isolates only in planta. Of course, $S$. nodorum populations used to rate these cultivars in the field may not have included the isolates used in this study.

We also found cases where MR cultivars showed sensitivity to one or more NEs produced by S. nodorum isolates. It is possible that those isolates in our sample are infrequent in field populations. If so, one would expect such MR cultivars, if widely planted, to rarely but occasionally display resistance "breakdowns" when they encounter S. nodorum isolates with the appropriate NE. Alternatively, the sensitivity of these MR lines to NEs may play a relatively minor role in disease, as has been shown in the case of SnTox3 (15). There may be other mechanisms, such as barriers to initial penetration, that account for a cultivar like LA01*425 having a high level of partial resistance to SNB in the field and still being sensitive to NEs produced by local $S$. nodorum isolates. These mechanisms would be especially useful to identify and select for in cases where sensitivity genes cannot be "bred out" because their resistance function is vital.

In cases where susceptible cultivars were insensitive, disease susceptibility appears to be conditioned, at least in part, by factors other than or in addition to effector sensitivity. For example, M6, the differential line for Snnl, has an MR phenotype but is sensitive to SnTox1. It has been shown that Snnl accounts for $\approx 60 \%$ of the phenotypic variation in the International Triticeae Mapping Initiative wheat population (20), suggesting that Snnl is very important but that other minor virulence factors (other quantitative trait loci) may also be involved in disease.

A next step in this research is to assess disease levels caused by these isolates on the 29 cultivars, in order to strengthen inferences about the relationship of disease resistance to effector sensitivity. Also, available molecular markers (11) can be used to survey southeastern U.S. wheat cultivars to confirm the relative absence of named Snn genes suggested by the present study. If the apparent virtual absence of Tsn1, Snn1, and Snn3 is confirmed in southeastern U.S. winter wheat germplasm, it raises the question of why a significant proportion of $S$. nodorum isolates in the southeastern United States carry the corresponding SnTox genes, in particular the widespread SnToxl. This may indicate that SnTox 1 or other NEs could have unidentified biochemical functions apart from inducing disease.

In summary, NEs appear to be an important component of the overall host-pathogen interaction in the wheat-S. nodorum pathosystem. We have provided evidence from a geographically broad sample of both pathogen and host that effector sensitivity influences overall resistance phenotype. Our study has shown that, although two and possibly three known NEs are produced by some $S$. nodorum isolates in the southeastern United States, the corresponding sensitivity genes are rare in wheat germplasm of the region, and uncharacterized effectors and sensitivity genes are likely more important in this region. Further research is needed to characterize these as-yet-unnamed effectors, especially those that are produced by S. nodorum isolates in cluster A (Fig. 2), which appear to be among those most frequently toxic to Southeastern wheats. The sensitivity genes which correspond to these novel effectors could then be "bred out" of regional germplasm, resulting in increased disease resistance.

\section{ACKNOWLEDGMENTS}

We thank B. Edge (Clemson University), C. Griffey (Virginia Polytechnic Institute and State University), A. Grybauskas (University of Maryland), G. Milus (University of Arkansas), D. West (University of Tennessee), and J. Youmans (University of Georgia) for providing wheat debris from which we obtained fungal isolates used in this study; K. Arceneaux, R. Bacon, J. Costa, J. Hancock, S. Harrison, J. Johnson, D. Marshall, B. Moreno, J. Mundell, J. P. Murphy, D. Van Sanford, and D. West for providing seed of wheat cultivars; and D. Holmes and J. Patton-Özkurt for excellent assistance with aspects of this study.

\section{LITERATURE CITED}

1. Abeysekara, N. S., Friesen, T. L., Keller, B., and Faris, J. D. 2009. Identification and characterization of a novel host-toxin interaction in the wheat-Stagonospora nodorum pathosystem. Theor. Appl. Genet. 120:117126.

2. Bhathal, J. S., Loughman, R., and Speijers, J. 2003. Yield reduction in wheat in relation to leaf disease from yellow $(\tan )$ spot and Septoria nodorum blotch. Eur. J. Plant Pathol. 109:435-443.

3. Bowman, D. T. 2010. Characteristics of North Carolina Wheat Varieties. North Carolina State University 229. Raleigh.

4. Costa, J. M., Bockelman, H. E., Brown-Guedira, G., Cambron, S. E., Chen, X., Cooper, A., Cowger, C., Dong, Y., Grybauskas, A., Jin, Y., Kolmer, J., Murphy, J. P., Sneller, C., and Souza, E. 2010. Registration of the soft red winter wheat germplasm MD01W233-06-1 resistant to Fusarium head blight. J. Plant Regul. 4:255-260.

5. Du, C. G., Nelson, L. R., and McDaniel, M. E. 1999. Diallel analysis of gene effects conditioning resistance to Stagonospora nodorum (Berk.) in wheat. Crop Sci. 39:686-690.

6. Eyal, Z. 1999. Breeding for resistance to Septoria and Stagonospora diseases in wheat. Pages 332-344 in: Septoria on Cereals: A Study of Pathosystems. J. A. Lucas, P. Bowyer, and H. M. Anderson, eds. CABI Publishing, New York.

7. Faris, J. D., Haen, K. M., and Gill, B. S. 2000. Saturation mapping of a gene-rich recombination hot spot region in wheat. Genetics 154:823-835.

8. Faris, J. D., Zhang, Z., Lu, H., Lu, S., Reddy, L., Cloutier, S., Fellers, J. P., Meinhardt, S. W., Rasmussen, J. B., Xu, S. S., Oliver, R. P., Simons, K. J., and Friesen, T. L. 2010. A unique wheat disease resistance-like gene governs effector-triggered susceptibility to necrotrophic pathogens. Proc. Natl. Acad. Sci. USA 107:13544-13549.

9. Fried, P. M., and Meister, E. 1987. Inheritance of leaf and head resistance of winter wheat to Septoria nodorum in a diallel cross. Phytopathology 77:1371-1375.

10. Friesen, T. L., Chu, C. G., Liu, Z. H., Xu, S. S., Halley, S., and Faris, J. D. 2009. Host-selective toxins produced by Stagonospora nodorum confer disease susceptibility in adult wheat plants under field conditions. Theor. Appl. Genet. 118:1489-1497.

11. Friesen, T. L., and Faris, J. D. 2010. Characterization of the wheatStagonospora nodorum disease system: What is the molecular basis of this quantitative necrotrophic disease interaction? Can. J. Plant Pathol. 32:20-28.

12. Friesen, T. L., Faris, J. D., Solomon, P. S., and Oliver, R. P. 2008. Hostspecific toxins: Effectors of necrotrophic pathogenicity. Cell. Microbiol. 10:1421-1428

13. Friesen, T. L., Meinhardt, S. W., and Faris, J. D. 2007. The Stagonospora nodorum-wheat pathosystem involves multiple proteinaceous hostselective toxins and corresponding host sensitivity genes that interact in an inverse gene-for-gene manner. Plant J. 51:681-692.

14. Friesen, T. L., Stuckenbrock, E. H., Liu, Z. H., Meinhardt, S. W., Ling, H., Faris, J. D., Rasmussen, J. B., Solomon, P. S., McDonald, B. A., and Oliver, R. P. 2006. Emergence of a new disease as a result of interspecific virulence gene transfer. Nat. Genet. 38:953-956.

15. Friesen, T. L., Zhang, Z., Solomon, P. S., Oliver, R. P., and Faris, J. D. 2008. Characterization of the interaction of a novel Stagonospora nodorum host-selective toxin with a wheat susceptibility gene. Plant Physiol. 146:682-692.

16. Li, G., Fang, T., Zhang, H., Xie, C., Li, H., Yang, T., Nevo, E., Fahima, T., Sun, Q., and Liu, Z. 2009. Molecular identification of a new powdery mildew resistance gene $\mathrm{Pm} 41$ on chromosome $3 \mathrm{BL}$ derived from wild 
emmer (Triticum turgidum var. dicoccoides). Theor. Appl. Genet. 119:531-539.

17. Liu, Z., Friesen, T. L., Ling, H., Meinhardt, S. W., Oliver, R. P., Rasmussen, J. B., and Faris, J. D. 2006. The Tsn1-ToxA interaction in the wheat-Stagonospora nodorum pathosystem parallels that of the wheat-tan spot system. Genome 49:1265-1273.

18. Liu, Z. H., Faris, J. D., Meinhardt, S. W., Ali, S., Rasmussen, J. B., and Friesen, T. L. 2004. Genetic and physical mapping of a gene conditioning sensitivity in wheat to a partially purified host-selective toxin produced by Stagonospora nodorum. Phytopathology 94:1056-1060.

19. Liu, Z. H., Faris, J. D., Oliver, R. P., Tan, K. C., Solomon, P. S., McDonald, M. C., McDonald, B. A., Nunez, A., Lu, S., Rasmussen, J. B., and Friesen, T. L. 2009. SnTox3 acts in effector triggered susceptibility to induce disease on wheat carrying the Snn 3 gene. PLoS Pathol. 5:e1000581. doi:10.1371/journal.ppat.1000581.

20. Liu, Z. H., Friesen, T. L., Rasmussen, J. B., Ali, S., Meinhardt, S. W., and Faris, J. D. 2004. Quantitative trait loci analysis and mapping of seedling resistance to Stagonospora nodorum leaf blotch in wheat. Phytopathology 94:1061-1067.

21. Liu, Z., Zhang, Z., Faris, J. D., Oliver, R. P., Syme, R., McDonald, M. C., McDonald, B. A., Solomon, P. S., Lu, S., Xu, S. S., and Friesen, T. L. 2012. The cysteine rich necrotrophic effector SnTox1 produced by Stagonospora nodorum triggers susceptibility of wheat lines harboring Snn1. PLoS Pathogens 8(1):e1002467. doi:10.1371/journal.ppat.1002467.

22. McDonald, B. A., and Martinez, J. P. 1990. Restriction fragment length polymorphisms in Septoria tritici occur at a high frequency. Curr. Genet. 17:133-138.

23. Reszka, E., Song, Q., Arseniuk, E., Cregan, P. B., and Ueng, P. P. 2007.
The QTL controlling partial resistance to Stagonospora nodorum blotch disease in winter triticale 'Bogo'. Plant Pathol. 16:161-167.

24. Singh, P. K., Feng, J., Mergoum, M., McCartney, C. A., and Hughes, G. R. 2009. Genetic analysis of seedling resistance to Stagonospora nodorum blotch in selected tetraploid and hexaploid wheat genotypes. Plant Breed. 128:118-123.

25. Solomon, P. S., Lowe, R. G. T., Tan, K. C., Waters, O. D. C., and Oliver, R. P. 2006. Stagonospora nodorum: Cause of Stagonospora nodorum blotch of wheat. Mol. Plant Pathol. 7:147-156.

26. Stukenbrock, E. H., and McDonald, B. A. 2007. Geographical variation and positive diversifying selection in the host-specific toxin SnToxA. Mol. Plant Pathol. 8:321-332.

27. Stukenbrock, E. H., and McDonald, B. A. 2009. Population genetics of fungal and oomycete effectors involved in gene-for-gene interactions. Mol. Plant-Microbe Interact. 22:371-380.

28. Tomás, A., Feng, G. H., Reeck, G. R., Bockus, W. W., and Leach, J. E. 1990. Purification of a cultivar-specific toxin from Pyrenophora triticirepentis, causal agent of tan spot of wheat. Mol. Plant-Microbe Interact. 3:221-224.

29. Wicki, W., Winzeler, M., Schmid, J. E., Stamp, P., and Messmer, M. 1999. Inheritance of resistance to leaf and glume blotch caused by Septoria nodorum (Berk.) in winter wheat. Theor. Appl. Genet. 99:1265-1272

30. Wolpert, T. J., Dunkle, L. D., and Ciuffetti, L. M. 2002. Host-selective toxins and avirulence determinants: What's in a name? Annu. Rev. Phytopathol. 40:251-285.

31. Yan, W. 2001. GGEbiplot-A Windows application for graphical analysis of multienvironment trial data and other types of two-way data. Agron. J. 93:1111-1118. 